\title{
Comparison of the Entropy- and Copula-based Precipitation-Streamflow Drought Indices for Assessing Agricultural Drought in Arid and Semi- arid Coastal Areas of Southern Iran
}

\author{
Javad Bazrafshan ( $\boldsymbol{\sim}$ jbazr@ut.ac.ir ) \\ University of Tehran https://orcid.org/0000-0002-6721-8990 \\ Zahra Azhdari \\ Hormozgan University
}

\section{Research Article}

Keywords: Drought, Precipitation, Streamflow, Copula, Entropy, Vegetation, Coastal basin, Iran

Posted Date: October 27th, 2021

DOl: https://doi.org/10.21203/rs.3.rs-943371/v1

License: (c) (i) This work is licensed under a Creative Commons Attribution 4.0 International License.

Read Full License 
1

Comparison of the Entropy- and Copula-based Precipitation-Streamflow Drought Indices for Assessing Agricultural Drought in Arid and Semi-arid Coastal Areas of Southern Iran

\section{Zahra Azhdari ${ }^{1}$, Javad Bazrafshan ${ }^{2 *}$}

${ }^{1} \mathrm{PhD}$ Student, Department of Natural Resources, Faculty of Agriculture and Natural Resources, University of Hormozgan. Email: z.azhdari67@gmail.com

${ }^{2 *}$ Corresponding Author, Associate Professor, Department of Irrigation and Reclamation Engineering, University of Tehran, Karaj, Iran. Email: jbazr@ut.ac.ir 
2 In arid and semi-arid regions, precipitation and seasonal streamflow are the two major sources of water for vegetation. The scarcity of these water sources has a detrimental effect on vegetation

4 cover degradation. The purpose of this research is to study the effect of meteorological and 5 hydrological droughts, and also their combined effects, on vegetation changes in seven coastal 6 sub-basins in southern Iran (part of the Bandar-Sedij and Kol-Mehran catchment). To track 7 meteorological and hydrological droughts, the Standardized Precipitation Index (SPI) and the 8 Streamflow Drought Index (SDI) were used. The copula function and the entropy approach (which 9 is developed in this research) were used to blend individual meteorological and hydrological drought indices, yielding hybrid indices called the Copula-based Drought Index and the Entropy-

11 based Drought Index (EnDI). The single (i.e., SPI and SDI) and hybrid drought indices (CoDI and 12 EnDI) were compared in terms of temporal behavior, drought severity and duration characteristics, 13 drought frequency, and a bivariate analysis of the drought severity-duration return period. The 14 results indicated that the rank correlation $\left(r_{s}\right)$ between SPI and SDI ranged between 0.327 and 150.726 in the studied sub-basins. However, the two hybrid indices CoDI and EnDI had extremely 16 high correlations $\left(r_{s} \geq 0.9\right)$. Despite the fact that meteorological droughts benefited both hybrid 17 drought indices more than hydrological droughts, the contribution of meteorological droughts to 18 EnDI was greater than that of CoDI. Over the study region, CoDI reported droughts that were both 19 longer and more severe than those recorded by EnDI. EnDI showed stronger associations with the 20 Normalized Vegetation Difference Index (NDVI) in nearly all the sub-basins, possibly because 21 precipitation has a greater effect on EnDI than it does on CoDI. EnDI was therefore recommended 22 as a superior index for estimating vegetation droughts throughout the research region.

23 Keywords: Drought, Precipitation, Streamflow, Copula, Entropy, Vegetation, Coastal basin, Iran. 


\section{Introduction}

2 Drought is a complex, recurrent, and multifaceted environmental hazard that has a wide range of

3 effects on ecosystems and society (Van Loon, 2015). Drought is defined as a temporary and

4 continuous period of available water shortage and its spatial and temporal characteristics vary from

5 one region to another region (Tallaksen and Van Lanen, 2004). Drought is described as a lack of

6 water caused by a variety of factors that vary depending on the climate of the region, such as a

7 lack of precipitation, soil moisture, streamflow, and groundwater level (Mishra and Singh, 2010).

8 Drought periods are irregular in arid and semi-arid regions, and they can persist for a long time

9 due to the unpredictable and erratic nature of precipitation in these regions. Streamflow in these regions is highly dependent on groundwater (Liu et al., 2020b) and exhibits long stagnation during

11 periods of low precipitation (Van Loon, 2015).

Drought indices are effective tools for quantifying drought characteristics such as the severity and duration and comparing different regions in terms of drought situation (Mishra and

14 Singh, 2011), and therefore applying these indices for drought risk management corresponding to the severity of deficiencies in a regions (Şen, 2015). Various indices have been developed to monitor meteorological, agricultural, and hydrological droughts. The most well-known index for monitoring meteorological drought is the Standardized Precipitation Index (SPI) (McKee et al., 1993), which is also recommended by World Meteorological Organization (WMO, 2012). SPI only uses precipitation data and is a versatile index for indirect monitoring of various types of deficiencies in soil moisture, surface water, and groundwater due to its capability to be calculated

21 on multiple time scales. Despite SPI's versatility, agricultural drought indices emphasize the direct

22 use of soil moisture deficiency as the main driver of this type of drought. However, in the cases 23 with limited access to soil moisture data, remote sensing indices such as the Normalized Difference 
1 Vegetation Index (NDVI) have also been used to monitor agricultural drought (Ebrahimi-Khusfi

2 et al., 2020; Pettorelli et al., 2005; Rahimzadeh Bajgiran et al., 2008; Shamsipour et al., 2008;

3 Vicente-Serrano et al., 2013). Several indices have been developed for monitoring hydrological

4 droughts, but the Streamflow Drought Index (SDI) is one of the most commonly utilized (Nalbantis

5 and Tsakiris, 2009).

6 Although drought indices provide useful information on drought features, none of them can

7 represent the overall drought conditions in an area. Therefore, it is recommended that composite

8 indices be used for effective drought risk management in a given area (de Jager and Vogt, 2015;

9 Hao and AghaKouchak, 2013; Kao and Govindaraju, 2010; Keyantash and Dracup, 2004; Ma et

10 al., 2015; Rad et al., 2017; Rajsekhar et al., 2015; Waseem et al., 2015). Various statistical

11 approaches are used to combine individual drought indices to construct composite drought indices.

12 Keyantash and Dracup (2004) presented the first composite drought index that integrate all

13 physical forms of droughts including meteorology, agriculture, and hydrology into one index

14 called the aggregate drought index using the Principal Component Analysis (PCA). The PCA

15 technique was also employed to construct composite indices in other studies (Azmi et al., 2016;

16 Bazrafshan et al., 2014; Bazrafshan et al., 2015). Kao and Govindaraju (2010) developed the joint

17 deficit index, which uses the copula functions to integrate meteorological and hydrological

18 droughts. Other composite drought indices based on copula functions have been developed, such

19 as the multivariate standardized drought index (Hao and AghaKouchak, 2013) for concurrent

20 monitoring of meteorological and agricultural droughts, and the standardized precipitation-

21 streamflow index (Rad et al., 2017) for concurrent monitoring of meteorological and hydrological

22 droughts. Another statistical approach, entropy weighted Euclidean distance, was developed by

23 Waseem et al. (2015) for monitoring meteorological, agricultural, and hydrological droughts, and 
1 it served as the basis for the formulation of composite indices in subsequent research (Chen et al.,

2 2020; Rajsekhar et al., 2015). Multiple linear regression (Liu et al., 2020a) and machine learning

3 (Shen et al., 2019) approaches have been used in some studies to construct composite drought

4 indices based on satellite remote sensing data. The capability of remote sensing indices was

5 evaluated in comparison with the ground-based Standardized Evapotranspiration Precipitation

6 Index (SEPI) (Vicente-Serrano et al., 2010).

7 Precipitation and seasonal streamflow are the two main sources of water supply for 8 vegetation in arid and semi-arid regions. In general, long-term scarcity of these water sources is 9 expected to put a considerable stress on vegetation cover (i.e., agricultural drought). Several 10 research on the link between meteorological, agricultural and hydrological droughts have been 11 conducted. Ma'rufah et al. (2017) showed that there is a significant correlation between Vegetation 12 Health Index (VHI) (an indicator of agricultural drought) with 3-month SPI time scale (an indicator 13 of meteorological drought) in Indonesia. Stagge et al. (2015) reported that 3-month SPI time scale 14 has the most probable impact on agricultural drought in Europe. Also, Mabrouk et al. (2020) found 15 that the highest correlation between meteorological drought (based on SPI) in Ethiopia with 16 hydrological drought (based on SDI) in Egypt occurs in 3-month and 6-month time scales. Al 17 Balasmeh et al. (2020) showed that the correlation of soil moisture (representative of agricultural 18 drought) with SPI is higher than SDI and about short-term droughts, 3-month time scale is 19 preferred to 1- and 2-month time scales.

20 The aim of this study is to examine the individual impact of meteorological and hydrological 21 droughts and their combined effects on vegetation changes (agricultural drought) in seven coastal 22 sub-basins in southern part of Iran (part of the Great Kal, Mehran, and Bandar e Sadij). For this 23 purpose, SPI and SDI indices were employed to track meteorological and hydrological droughts, 
respectively. NDVI was used to track droughts in vegetation cover (or agricultural droughts).

Hybrid indices were developed utilizing two approaches of copula function and entropy weighting which their capability to identify periods of drought is also examined and compared. Due to the arid and semi-arid climate of the study area, it is expected that precipitation has a greater role in vegetation changes than streamflow. Also, hybrid indices are expected to explain a higher percentage of variability in vegetation due to the combined effect of SPI and SDI in their formulations. The novelty of this study is the development of a new hybrid drought index based on the entropy weighting approach.

\section{Data and Methods}

\subsection{Study Area and Data}

The basin under consideration is part of Kal-Mehran-Bandar Sadij basins, which are located in southern Iran (Fig.1). This basin has a total size of $71483.26 \mathrm{~km}^{2}$ and is located between latitudes of $25.75^{\circ} \mathrm{N}-29^{\circ} \mathrm{N}$ and longitudes of $45.52^{\circ} \mathrm{E}-95.57^{\circ} \mathrm{E}$. The study area comprises seven sub-basins: Berantin (BRB), Hajiabad (HRB), Darb-E-Ghale (DERB), Dezhgan (DZRB), Mazabi (MRB), Kahourestan (KRB), and Sikhoran (SRB). The climate of region is warm and dry, with an annual average temperature of $27^{\circ} \mathrm{C}$ and an annual average precipitation of $215.8 \mathrm{~mm}$. The spatiotemporal pattern of rainfall over the study area is irregular, and the majority of rivers are seasonal.

Monthly precipitation data from 25 rain gauge stations and average monthly streamflow volume data from 13 hydrometric stations (placed inside the basin) were utilized in this investigation. Fig. 1 depicts the location of meteorological and hydrological stations. All groundbased data were collected from Iran Meteorological Organization and Ministry of Power and span the period 1986-2017 and. Furthermore, remote sensing data of Land Surface Temperature (LST) and Normalized Difference Vegetation Index (NDVI) from the Terra satellite's Moderate 
1 Resolution Imaging Spectroradiometer (MODIS) Sensor were utilized to assess the impacts of

2 hydro-meteorological drought on vegetation. These data, which span the period 2000-2017, were

3 downloaded from NASA's Web Portal (http://modis.gsfc.nasa.gov/data) and have a spatial

4 resolution of $1 \mathrm{~km}^{2}$, with the desired tiles of $\mathrm{h} 22 \mathrm{v} 06$ and h23v06 for the study area.

\section{$5 \quad 2.2$ Methods}

\section{$6 \quad$ 2.2.1 Applied Drought Indices}

7 The drought indices used in this study were classified into two groups: univariate indices and

8 bivariate indices. At first, meteorological and hydrological droughts were quantified separately

9 using the Standardized Precipitation Index (SPI) and Streamflow Drought Index (SDI),

10 respectively. The Copula function and entropy statistical approaches were then utilized to combine

11 SPI and SDI into a new combined drought index known as the precipitation-streamflow drought

12 index. It should be noted that all indices were calculated over a 3-month time scale. The reason for

13 using such a short time frame (3 months) is to assess the efficacy of indices used to monitor

14 agricultural droughts in the research region. It should be mentioned that in many agricultural

15 drought research, the 3-month time scale is utilized as a common study scale. These indices are 16 described in detail in the following sections.

\section{$17 \quad$ 2.2.1.1 Standardized Precipitation Index}

18 McKee et al. (1993) developed the Standardized Precipitation Index (SPI) to track drought events 19 in Colorado. SPI requires only monthly precipitation data as input. The capability to calculate at 20 multiple time scales is a key aspect of SPI. Short-term SPI time scales (e.g., three months, the time 21 period utilized in this study) influence vegetation, whereas longer SPI time scales affect surface 22 and groundwater resources. The SPI is calculated by calculating precipitation probability in each 23 time frame. Therefore, the first step in calculating this index is to fit an appropriate statistical 
1 distribution to precipitation data. According to Edwards and McKee (1997) studies, the gamma

2 distribution fitted properly to the US monthly precipitation data and the theory underlying the SPI

3 was initially presented on the basis of this distribution. The gamma probability density function is

4 defined as follows:

$5 \quad f_{X}(x)=\frac{(x / \beta)^{\alpha-1} \exp (-x / \beta)}{\beta \Gamma(\alpha)}$, for $\quad x, \alpha, \beta>0$

6 where, $\alpha$ is the shape parameter, $\beta$ is the scale parameter, $x$ is the precipitation value, and $\Gamma(\alpha)$ is

7 the gamma function. In the next step, the cumulative probability distribution of precipitation is

8 calculated as below:

$9 \quad F_{X}(x)=\frac{1}{\beta \Gamma(\alpha)} \int_{0}^{x}\left(\frac{x}{\beta}\right)^{\alpha-1} \exp \left(-\frac{x}{\beta}\right) d x$

10 Due to the fact that the gamma function is not specified for $x=0$ (zero precipitation) and the

11 distribution of precipitation may include zero values, the total cumulative probability function,

12 which also contains zero precipitation, will be as follows:

$13 \quad H_{X}(x)=p+(1-p) F_{X}(x)$

14 where $p$ is the probability of zero precipitation. After calculating the total cumulative function

$15\left(H_{X}(x)\right)$, the equal probability transformation from $H_{X}(x)$ to the standard normal distribution $\mathrm{Z}$

16 (or SPI) with a mean of zero and a variance of one is carried out according to the following formula:

$17 S P I_{i j}=\varphi^{-1}\left(H_{X}\left(x_{i j}\right)\right)$

18 where $x_{i j}$ is the cumulative precipitation in the $j$ th month and $i$ th year and $\varphi^{-1}($.$) is the inverse$

19 standard normal function. Table 1 shows the SPI classes for drought $(S P I \leq-1)$, near normal

$20 \quad(-1 \leq S P I \leq 1)$ and wet period $(S P I>1)$. 


\subsubsection{Streamflow Drought Index}

2 The Streamflow Drought Index (SDI) was presented by Nalbantis and Tsakiris (2009). The SDI

3 calculation is mathematically similar to the SPI. The SDI methodology was first described based

4 on the fit of the two-parameter log-normal distribution to monthly streamflow data. The SDI

5 equation is as follows:

$6 S D I_{i j}=\frac{y_{i j}-\bar{y}_{j}}{s_{j}}$

7 where $y_{i j}$ is the natural logarithm of the cumulative streamflow volume in month $j$ and year $i ; \bar{y}_{j}$

8 is the mean, and $s_{j}$ is the standard deviation of $y_{i j}$. In this study, SDI was calculated as SPI in a 3-

9 month time window. According to Table 1, the SDI is classified the same as the SPI.

$10 \quad$ 2.2.1.3 Copula-based Precipitation-Streamflow Drought Index

11 According to Sklar's theorem (Sklar, 1959), the cumulative bivariate distribution function

$12 H(X, Y)$ for two continuous random variables $X$ and $Y$ with marginal cumulative distribution

13 functions $F_{X}(x)$ and $G_{Y}(y)$ can be defined as follows:

$14 H_{(X, Y)}(x, y)=C\left\{F_{X}(x), G_{Y}(y)\right\}=C(u, v), x, y \in R$

15 Where $F_{X}(x)=u$ and $G_{Y}(y)=v$ are the marginal distributions of the two variables $X$ and $Y$ with

16 the uniform distribution functions $U[0,1]$, and $C:[0,1]^{2} \rightarrow[0,1]$ is a copula function that models

17 the dependencies between marginal distributions. Copulas, either empirical or theoretical, can be

18 used to model this dependence. The empirical copula is based on marginal empirical functions of

19 the study variables, whereas the theoretical copulas have specific mathematical forms, some of

20 which are shown in Table 2. The empirical copula is used in this study to construct a hybrid

21 precipitation-streamflow drought index. The following are the steps for calculating this index (Kao

22 and Govindaraju, 2010): 
1

$2 Y=S D I$, respectively, the empirical copula function $C_{n}(u, v)$ of both for each month of the year

3 is stated as follows:

$4 \quad C_{n}(u, v)=\frac{1}{n} \sum_{l=1}^{n} I\left(\frac{R_{l}}{n+1} \leq u, \frac{s_{l}}{n+1} \leq v\right)$

5 where, $R_{l}$ and $S_{l}$ are the ascending ranks of the two variables $x_{l}$ and $y_{l}$, respectively, and $n$ is the

6 sample size. $I(A)$ is an indicator function of statement $A$. If $A$ is true, then $I(A)=1$, otherwise

$7 \quad I(A)=0$.

8 - Calculate the cumulative distribution of copula function, which is called the Kendall distribution

9 function:

$10 \quad K_{c, i j}(q)=P\left[C\left(u_{i j}, v_{i j}\right) \leq q\right]$

11 in which $C\left(u_{i j}, v_{i j}\right)=P\left[U \leq u_{i j}, V \leq u_{i j}\right]=q$ denotes the joint cumulative probability of SPI

12 and SDI in month $j$ and year $i$ and $K_{c, i j}(q)$ represents the Kendall distribution function. In fact,

13 the Kendall function calculates the probability of all non-exceedance copula values of $q$. As a

14 result, the dimensions of data are decreased from two to one. It is worth noting that a Kendall

15 function was calculated for each month of the calendar year. Therefore, 12 Kendall functions were

16 obtained, one for each of the 12 months of the year.

17 - Deriving the Copula-based precipitation-streamflow Drought Index (CoDI) from the following

18 equation by taking the inverse standard normal of the Kendall function:

$19 \quad \operatorname{CoDI}_{i j}=\varphi^{-1}\left(K_{c, i j}(q)\right)$

20 where $\varphi^{-1}($.$) is the inverse standard normal function. Positive CoDI values indicate wet conditions$ 21 and negative values correspond to drought conditions. The CoDI classes, like other standardized 22 drought indices, are as shown in Table 1. 


\subsubsection{Entropy-based Precipitation-Streamflow Drought Index}

2 The hybrid drought index proposed in this study is based on the SPI and SDI entropy weights.

3 First, the weight of each variable in each month of the year is obtained based on the entropy method

4 from the following equation (Shannon, 1948; Singh, 2015):

$5 \quad W_{j k}=\frac{1-E_{j k}}{\sum_{k=1}^{2}\left(1-E_{j k}\right)} \quad, \quad$ for $k=1,2$ and $j=1, \ldots, 12$

6 where, $W_{j k}$ is the weight corresponds to the $k$ th variable (SPI or SDI) in the $j$ th month and satisfy

7 for the condition $\sum_{k=1}^{2} W_{j k}=1$ for month $j . E_{j k}$ is entropy which is calculated from the following 8 equation:

$9 \quad E_{j k}=-\frac{1}{\ln (m)} \sum_{i=1}^{m} N_{i j k} \ln \left(N_{i j k}\right)$, for $k=1,2$ and $j=1, \ldots, 12$

10

11

$12 \quad N_{i j k}=\frac{\left|S_{i j k}\right|}{\sum_{i=1}^{m}\left|S_{i j k}\right|}$, for $k=1,2$ and $j=1, \ldots, 12$

13

14

$15 \quad E n D I_{i j}=W_{j 1} \cdot S P I_{i j}+W_{j 2} \cdot S D I_{i j}$

16 in which $W_{j 1}$ and $W_{j 2}$ are the weights of SPI and SDI indices in the $j$ th month, respectively. Table

171 can be used for classifying EnDI.

\subsubsection{Spearman Rank Correlation Coefficient}

19 Spearman rank correlation coefficient determines the nonlinear dependence between two random 20 variables $X$ and $Y$. If $R_{i}$ is the rank of variable $x_{i}$ between $x_{1}, \ldots, x_{n}$, and $T_{i}$ is the rank of variable $21 y_{i}$ between $y_{1}, \ldots, y_{n}$, the Spearman rank correlation coefficient of $X$ and $Y$ is defined as follows: 
$1 \quad r_{s}(X, Y)=\operatorname{Cor}\left(R_{i}, T_{i}\right)=\frac{12}{n(n+1)(n-1)} \sum_{i=1}^{n} R_{i} T_{i}-3 \frac{n+1}{n-1}$

2 In this study, Spearman correlation coefficient was used to analyze the correlation between

3 different drought indices, between NDVI and LST, between the single and hybrid drought indices,

4 and between NDVI and each of four drought indices used in this study. In addition, Spearman

5 correlation is directly related to the copula function; hence, the larger the value of this measure,

6 the stronger the correlation between the two copula marginal functions. The value of Spearman

7 correlation varies between -1 to +1 . Positive correlation indicates a direct relationship between two

8 random variables and negative correlation shows an inverse relationship.

$9 \quad$ 2.2.3 Frequency Analysis of Drought Characteristics

10 A drought phenomenon happens when a specific drought index is less than zero. Accepting this

11 threshold allows for the determination of the two most important features of any drought

12 phenomenon, namely the duration (D) and severity (S) of the drought (Fig. 2). The duration of a

13 drought, according to this definition, is equal to the number of months in which the drought index

14 is less than zero. Drought severity is also defined as the area below the zero threshold of the

15 drought index. The severity and duration of a drought are two dependent variables, so as the

16 duration of the drought increases, the severity is expected to increase. Therefore, this dependency

17 provides the possibility to use copula function for modeling the relationship between the drought

18 duration and severity and to calculate the drought return period. In this study, six probability

19 distribution functions including Normal, Lognormal, Weibull, Exponential, Gamma, and Logistic

20 were fitted as candidate marginal functions on the characteristics of drought duration and severity.

21 Six candidate copula functions including Frank, Clayton, Joe (Archimedean copulas), Normal, and

22 T-student (elliptical copulas) (their mathematical forms are shown in Table 2) were examined for

23 modeling the drought severity-duration relationship. The parameters of the marginal and copula 
1 functions were estimated using the maximum likelihood method (Requena et al., 2013). Finally,

2 the return period of drought events lasting longer than the specified duration $\left(d_{i}\right)$ and severity $\left(s_{i}\right)$

3 was estimated according to the following equation (Rashid and Beecham, 2019):

$4 \quad T\left(S \geq s_{i}, D \geq d_{i}\right)=\frac{\mu}{1-F_{D}\left(d_{i}\right)-F_{S}\left(s_{i}\right)+C_{D S}\left(F_{D}\left(d_{i}\right), F_{S}\left(s_{i}\right)\right)}$

5 where, $F_{D}$ and $F_{S}$ are the marginal and cumulative probability distribution functions of duration

6 and severity of a drought, respectively, $\mu$ is the mean interarrival time of drought events, which is

7 defined as the ratio of the number of years to the number of drought events in the statistical period.

8 In the case of floods, the value of $\mu=1$, but it is different in the case of drought events which may

9 last longer than one year or may have several drought events in one year. The parameters of the

10 marginal and copula functions were estimated, and the return period was calculated, using a copula

11 package built in the R environment (Hofert and Maechler, 2011).

\section{3. Results and Discussion}

\section{$13 \quad 3.1$ Comparison of SPI and SDI}

14 Prior to calculating the indices, the fitness of six candidate distributions, including Weibull,

15 Gamma, Normal, Lognormal, Logistic, and Exponential, on the precipitation and streamflow

16 volume aggregated on a 3-month time scale was examined. The results of Kolmogorov-Smirnov

17 test confirmed that the Gamma distribution fits the cumulated 3-month precipitation data better

18 than other statistical distributions in all studied sub-basins. In the case of streamflow, the

19 Lognormal distribution was preferred in all sub-basins except the BRB, where the Weibull

20

22 distribution fitted the data more appropriately.

SPI and SDI were calculated using the best distributions fitted to the 3-month precipitation and streamflow data for the studied sub-basins, respectively. Fig. 3 depicts the results of 
1 calculating the two indices. The SPI fluctuates more regularly than the SDI in all sub-basins.

2 Instead, SDI revealed prolonged drought/wet periods in some sub-basins that were not observed

3 in SPI time series. For example, the HRB sub-basin experienced a 4-year streamflow drought

4 (2013-2016), whereas the SPI was often higher than average over the same time period. Similarly,

5 prior to 2000, the SDI-based BRB sub-basin consistently exhibited normal or higher-than-normal

6 conditions, but the SPI-based sub-basin alternated between drought and wet years. However,

7 adaptability to dry and wet periods increased in this sub-basin after 2000. There appears to be a

8 strong negative decreasing trend in the SDI series, which has resulted in normal and higher-than-

9 normal conditions in the BRB sub-basin prior to 2000. Another interesting point is the 2017 severe

10 wet period in SDI, which was reported in all sub-basins except BRB. The SPI value in this wet

11 year, however, is not significantly different from other wet years in the whole record period.

12 The Spearman rank correlation coefficient between SDI and SPI was computed for each sub-

13 basin and found to range between 0.327 (MRB sub-basin) and 0.726 (DZRB sub-basin). In fact,

14 three MRB, SRB and HRB sub-basins, which are located in the eastern part of the study area (Fig.

15 1), had the lowest correlations between meteorological and hydrological droughts $\left(r_{s}<0.5\right)$. In

16 most years of the statistical period, there was no much adaptation between SPI and SDI in the

17 mentioned sub-basins. Instead, there was a relatively good correlation $\left(r_{s}>0.6\right)$ between the two 18 indices in the western sub-basins.

\subsection{Comparison of EnDI and CoDI}

Fig. 4 displays the results of computing the hybrid drought indices (EnDI and CoDI). According

21 to this figure, there is a large adaptation between the CoDI and EnDI time series in all sub-basins

22 studied. The Spearman rank correlation coefficients between the two hybrid indices across sub-

23 basins ranged from 0.918 (HRB sub-basin) to 0.992 (DZRB sub-basin). Such strong correlations 
between EnDI and CoDI indicate that high/low correlations between single drought indices (SPI and SDI) have no considerable effect on the dependence of the two hybrid indices. In DZRB subbasin, where the two hybrid indices have the highest correlation, SPI and SDI also show the highest correlation. However, while the lowest correlation between SPI and SDI was observed in MRB sub-basin, the lowest correlation between the hybrid indices was related to HRB sub-basin. Therefore, it can be concluded that with higher correlation between individual indices, it is not expected that the hybrid indices developed in this study also have a high correlation.

To get an overview, Fig. 5 shows the $95 \%$ confidence level of the mean correlation coefficients between different drought indices across the studied sub-basins. According to this figure, the mean correlation coefficient between EnDI and SPI is higher than that between EnDI and SDI. Similar connections also exist between CoDI with each of the single indices. Therefore, it is possible to conclude that both CoDI and EnDI give more contribution to SPI than SDI. SPI, however, contributes more to the construction of EnDI than CoDI. The contribution of SDI, on the other hand, is more evident in construction of CoDI than EnDI.

\subsection{Drought Severity-Duration Analysis}

The two hybrid indices CoDI and EnDI were also compared in terms of drought severity and duration characteristics (Fig. 6). As seen in this figure, CoDI has documented longer and more severe droughts than EnDI, particularly in the HRB, KRB and DZRB sub-basins. For example, CoDI recorded a 30-month drought period (06/2014-11/2016) in HRB sub-basin, the longest drought duration experienced across the study area. When using EnDI, the longest drought was split into three smaller drought episodes. Another example is the CoDI-identified 21-month drought period (07/2007-03/2009), which EnDI has split it into three shorter drought episodes. However, the scatter diagram of drought severity vs. drought duration for both hybrid indices are 
1 almost identical in the BRB, DERB and MRB sub-basins. In the SRB sub-basin, the two hybrid

2 indices are not significantly different in terms of drought duration, but CoDI has reported more

3 severe droughts than EnDI.

\section{$4 \quad 3.4$ Frequency Analysis}

5 Two hybrid drought indices used in this study were analyzed and compared in terms of the

6 frequency of different classes of drought, near normal, and wet period, as seen in Fig. 7. EnDI did

7 not report severe droughts in the $\mathrm{HRB}, \mathrm{KRB}, \mathrm{BRB}$, and $\mathrm{SRB}$ sub-basins, and revealed severe and

8 very severe droughts in the DZRB and MRB sub-basins. The zero frequency in severe/very severe

9 classes of droughts has been offset by an increase in the frequency of moderate/severe classes of

10 droughts. This index has reported the occurrence of all drought classes just in the DERB sub-basin.

11 While CoDI has not reported zero frequency in any of the sub-basins and drought's classes. This

12 finding was not surprising for CoDI because it follows the standard normal distribution, but EnDI

13 is based on the weighting coefficients of the individual SPI and SDI indices and so has no unique

14 distribution.

\section{$15 \quad 3.5$ Return Period Analysis of Drought Severity and Duration}

16 Two hybrid drought indices used in this study were examined in terms of univariate and bivariate

17 return period analysis of drought severity and duration. To this end, first, the marginal probability

18 distribution of each drought characteristic (i.e., severity and duration) was determined. Then, five

19 well-known bivariate copulas (Table 2) were fitted to the dependence structure of drought severity

20 and duration, and one with the lowest value of the Cramer-von Mises test (Genest and Favre, 2007)

21 was selected as the best copula among the others. The chosen copulas for the studied sub-basins

22 are presented in Table 3. The table indicates that the best copula function was not the same in all 23 sub-basins. The Normal copula (in MRB sub-basin) and the Joe copula (in SRB sub-basin) were 
1 introduced as the best models fitting the drought severity and duration derived from CoDI and

2 EnDI. In other sub-basins, the two hybrid indices differed in terms of the type of selected copula

3 function. All five copula functions used in this study were optimal in at least one case.

5 for six return period levels of 2, 5, 10, 20, 50, and 100 years (column 2 in Table 3) were estimated

6 from the best marginal distributions fitted to the drought characteristics $s$ and $d$. In bivariate case,

7 joint return period of $s$ and $d$ was estimated for the condition $S \geq s$ and $D \geq d$ using Equation

8 15. For example, based on CoDI calculated in HRB sub-basin, the return period of $S \geq 3.4$ is 2

9 years, and the return period of $D \geq 6.0$ also is 2 years. For concurrent occurrence of two events

$10 S \geq 3.4$ and $D \geq 6.0$, the bivariate return period (column 5 in Table 3 ) increases to 2.5 years.

11 Based on EnDI calculated in the same sub-basin, a drought event with $S \geq 2.8$ or $D \geq 4.2$ is

12 expected to return each 2 years. While the return period of a drought event with joint occurrence

13 of $S \geq 2.8$ and $D \geq 4.2$ increases to 2.3 years. As seen in the table, all bivariate return periods of

14 drought characteristics are greater than the corresponding univariate ones. This result is most

15 important when evaluating drought risks for managing and allocating water resources to different

16 activities in the study area. In some sub-basins such as HRB and MRB, there is no considerable

17 differences between CoDI- and EnDI-based bivariate return periods. In other sub-basins, two

18 hybrid indices indicated significant differences between their bivariate return periods, especially

19 for univariate return period levels of 50 and 100 years.

\subsection{Vegetation Response to Drought Indices}

21 The Normalized Difference Vegetation Index (NDVI) and Land Surface Temperature (LST) are

22 inversely linked across vegetation regions. In other words, when NDVI rises, LST falls owing to 23 evaporative cooling over plant cover (Karnieli et al., 2010; Sun and Kafatos, 2007). The negative 
associations between NDVI and LST in each of the examined sub-basins are confirmed in Fig. 8, allowing us to assess vegetation response to drought stress across the study area. The correlation coefficients range from -0.3 (HRB sub-basin) to -0.6 (DZRB), and they are all statistically significant at the $95 \%$ confidence level.

The results of the correlation analysis between NDVI and ground-based drought indices (SPI, SDI, CoDI, and EnDI) in the studied sub-basins are presented in Table 5. As seen in the table, NDVI has the highest correlation with the entropy-based drought index (EnDI) in all subbasins except MRB. In the MRB sub-basin, the highest correlation between NDVI and SDI was obtained. Based on mean correlation coefficients across the sub-basins, NDVI has the highest correlation with EnDI. As a result of the correlation analysis, the EnDI is a better indicator than the other indices employed in this study for evaluating the real-time impact of drought on vegetation cover. In addition to the simultaneous associations, Table 5 shows the correlation between NDVI in the current month (time $t$ ) and each drought index from the prior month (time $t-1)$. The results revealed that EnDI is a superior predictor of NDVI response to drought in four sub-basins: HRB, KRB, DERB, and MRB. SPI and SDI were superior indices to predict the impact of drought on vegetation in the BRB and SRB sub-basins, and in the DZRB sub-basin. It should be highlighted that in none of the sub-basins, CoDI was the first priority index.

\section{Conclusion}

In this work, the efficiency of two single drought indices, SPI and SDI, and two hybrid indices, CoDI and EnDI, for assessing drought impacts on vegetation cover in seven coastal sub-basins in southern Iran was investigated. Preliminary data analysis revealed that the Gamma (Log-Normal) distributions fit the cumulative 3-month precipitation (streamflow) data the best in nearly all of the examined sub-basins. Because of the seasonality of river flows in the sub-basins of interest, 
1

moderate to reasonably high correlations between SPI and SDI were detected. In this work, a hybrid drought index called Entropy-based Drought Index (EnDI) was established, which is based on a combination of SPI and SDI and uses the entropy-weighting approach. Furthermore, a Copula-based Drought Index (CoDI) was constructed by combining SPI and SDI with the best copula model fitted to these indices. In this study, the drought indices utilized were compared in terms of several statistical characteristics. The results indicated a strong connection between two hybrid indicators in all sub-basins studied. Both hybrid indices exhibited a stronger relationship with SPI than SDI. The hybrid indices, however, differed in their ability to reflect the features of the most severe drought episodes (severity and length of extreme droughts) in some sub-basins. In several sub-basins, the EnDI hybrid index did not report severe or very severe drought, but the CoDI indicated frequencies for each drought/wet class in all sub-basins. The most suitable (fitted) copula function was not the same in all sub-basins, according to a bivariate analysis of drought severity-duration utilizing copula functions. The analysis of univariate and bivariate return periods of drought characteristics revealed that CoDI reported longer and more severe droughts than EnDI for a given return period. In some sub-basins, the return period of drought severity-duration based on CoDI was clearly different from EnDI. Correlation analysis of NDVI (representative of agricultural drought) with zero- and one-month lag of the drought indices indicated that NDVI had a higher correlation with EnDI than the other drought indices in nearly all sub-basins examined. As a result, the EnDI hybrid index developed in this work was suggested for monitoring and predicting vegetation response to drought throughout the sub-basins studied.

\section{Acknowledgments}

This article was prepared during the study opportunity of Ms. Zahra Ajdari (PhD student of Hormozgan University) at the University of Tehran, which is hereby thanked and appreciated. 


\section{Ethical Approval}

2 Not applicable.

\section{Consent to Participate}

$4 \quad$ Not applicable.

\section{Consent to Publish}

$6 \quad$ Not applicable.

\section{Competing Interests}

8 The authors declare that they have no conflict of interest.

$9 \quad$ Availability of data and materials

10 Readers can contact authors for availability of data and materials.

\section{References}

Al Balasmeh, O., Babbar, R., and Karmaker, T. (2020). A hybrid drought index for drought assessment in Wadi Shueib catchment area in Jordan. Journal of Hydroinformatics 22, 937956.

Azmi, M., Rüdiger, C., and Walker, J. P. (2016). A data fusion-based drought index. Water Resources Research 52, 2222-2239.

Bazrafshan, J., Hejabi, S., and Rahimi, J. (2014). Drought Monitoring Using the Multivariate Standardized Precipitation Index (MSPI). Water Resources Management 28, 1045-1060.

Bazrafshan, J., Nadi, M., and Ghorbani, K. (2015). Comparison of Empirical Copula-Based Joint Deficit Index (JDI) and Multivariate Standardized Precipitation Index (MSPI) for Drought Monitoring in Iran. Water Resources Management 29, 2027-2044.

Chen, S., Zhong, W., Pan, S., Xie, Q., and Kim, T.-W. (2020). Comprehensive Drought Assessment Using a Modified Composite Drought index: A Case Study in Hubei Province, China. Water 12, 462.

de Jager, A. L., and Vogt, J. V. (2015). Analyzing the Combined Drought Indicator (CDI): Demonstration and Analysis of its Evolution during Spring and Summer 2013- 2014. Agriculture and Agricultural Science Procedia 4, 222-231. 
Ebrahimi-Khusfi, Z., Mirakbari, M., Ebrahimi-Khusfi, M., and Taghizadeh-Mehrjardi, R. (2020). Impacts of vegetation anomalies and agricultural drought on wind erosion over Iran from 2000 to 2018. Applied Geography 125, 102330.

Edwards, D. C., and McKee, T. B. (1997). "Characteristics of 20th Century Drought in the United States at Multiple Time Scales," Department of Atmospheric Science, Colorado State University, Fort Collins.

Genest, C., and Favre, A.-C. (2007). Everything You Always Wanted to Know about Copula Modeling but Were Afraid to Ask. Journal of Hydrologic Engineering 12, 347-368.

Hao, Z., and AghaKouchak, A. (2013). Multivariate Standardized Drought Index: A parametric multi-index model. Advances in Water Resources 57, 12-18.

Hofert, M., and Maechler, M. (2011). Nested Archimedean Copulas Meet R: The nacopula Package. 2011 39, 20.

Kao, S.-C., and Govindaraju, R. S. (2010). A copula-based joint deficit index for droughts. Journal of Hydrology 380, 121-134.

Karnieli, A., Agam, N., Pinker, R. T., Anderson, M., Imhoff, M. L., Gutman, G. G., Panov, N., and Goldberg, A. (2010). Use of NDVI and Land Surface Temperature for Drought Assessment: Merits and Limitations. Journal of Climate 23, 618-633.

Keyantash, J. A., and Dracup, J. A. (2004). An aggregate drought index: Assessing drought severity based on fluctuations in the hydrologic cycle and surface water storage. Water Resources Research 40, W09304.

Liu, Q., Zhang, S., Zhang, H., Bai, Y., and Zhang, J. (2020a). Monitoring drought using composite drought indices based on remote sensing. Science of The Total Environment 711, 134585.

Liu, W., Park, S., Bailey, R. T., Molina-Navarro, E., Andersen, H. E., Thodsen, H., Nielsen, A., Jeppesen, E., Jensen, J. S., Jensen, J. B., and Trolle, D. (2020b). Quantifying the streamflow response to groundwater abstractions for irrigation or drinking water at catchment scale using SWAT and SWAT-MODFLOW. Environmental Sciences Europe $32,113$.

Ma, M., Ren, L., Singh, V. P., Tu, X., Jiang, S., and Liu, Y. (2015). Evaluation and application of the SPDI-JDI for droughts in Texas, USA. Journal of Hydrology 521, 34-45.

Ma'rufah, U., Hidayat, R., and Prasasti, I. (2017). Analysis of relationship between meteorological and agricultural drought using standardized precipitation index and vegetation health index. IOP Conference Series: Earth and Environmental Science 54, 012008.

Mabrouk, E. H., Moursy, F. I., Mohamed, M. A. E.-H., and Omer, M. E. D. M. (2020). Estimate of correlation between the metrological drought on Ethiopia the Hydrological drought on Egypt. Future of Food: Journal on Food, Agriculture and Society 8.

McKee, T. B., Doeskin, N. J., and Kleist, J. (1993). The relationship of drought frequency and duration to time scales. In "Proceedings of the eighth conference on applied climatology", pp. 179-184. American Meteorological Society, Anaheim, CA.

Mishra, A. K., and Singh, V. P. (2010). A review of drought concepts. Journal of Hydrology 391, 202-216.

Mishra, A. K., and Singh, V. P. (2011). Drought modeling - A review. Journal of Hydrology 403, $157-175$.

Nalbantis, I., and Tsakiris, G. (2009). Assessment of Hydrological Drought Revisited. Water Resources Management 23, 881-897. 
Pettorelli, N., Vik, J. O., Mysterud, A., Gaillard, J.-M., Tucker, C. J., and Stenseth, N. C. (2005). Using the satellite-derived NDVI to assess ecological responses to environmental change. Trends in Ecology \& Evolution 20, 503-510.

Rad, A. M., Ghahraman, B., Khalili, D., Ghahremani, Z., and Ardakani, S. A. (2017). Integrated meteorological and hydrological drought model: A management tool for proactive water resources planning of semi-arid regions. Advances in Water Resources 107, 336-353.

Rahimzadeh Bajgiran, P., Darvishsefat, A. A., Khalili, A., and Makhdoum, M. F. (2008). Using AVHRR-based vegetation indices for drought monitoring in the Northwest of Iran. Journal of Arid Environments 72, 1086-1096.

Rajsekhar, D., Singh, V. P., and Mishra, A. K. (2015). Multivariate drought index: An information theory based approach for integrated drought assessment. Journal of Hydrology 526, 164182.

Rashid, M. M., and Beecham, S. (2019). Development of a non-stationary Standardized Precipitation Index and its application to a South Australian climate. Science of The Total Environment 657, 882-892.

Requena, A. I., Mediero, L., and Garrote, L. (2013). A bivariate return period based on copulas for hydrologic dam design: accounting for reservoir routing in risk estimation. Hydrol. Earth Syst. Sci. 17, 3023-3038.

Şen, Z. (2015). Chapter Seven - Drought Hazard Mitigation and Risk. In "Applied Drought Modeling, Prediction, and Mitigation", pp. 393-459. Elsevier, Boston.

Shamsipour, A. A., AlaviPanah, S. K., Mohammadi, H., Azizi, A., and Khoshakhlagh, F. (2008). An analysis of drought events for central plains of Iran through an employment of NOAAAVHRR data. Desert 13, 105-115.

Shannon, C. E. (1948). A mathematical theory of communication. The Bell System Technical Journal 27, 379-423.

Shen, R., Huang, A., Li, B., and Guo, J. (2019). Construction of a drought monitoring model using deep learning based on multi-source remote sensing data. International Journal of Applied Earth Observation and Geoinformation 79, 48-57.

Singh, V. P. (2015). "Entropy Theory in Hydrologic Science and Engineering," McGraw-Hill Education, New York.

Stagge, J. H., Kohn, I., Tallaksen, L. M., and Stahl, K. (2015). Modeling drought impact occurrence based on meteorological drought indices in Europe. Journal of Hydrology 530, $37-50$.

Sun, D., and Kafatos, M. (2007). Note on the NDVI-LST relationship and the use of temperaturerelated drought indices over North America. Geophysical Research Letters 34.

Tallaksen, L. M., and Van Lanen, H. A. J. (2004). "Hydrological drought: processes and estimation methods for streamflow and groundwater," Elsevier Science B.V., Amsterdam, the Netherlands.

Van Loon, A. F. (2015). Hydrological drought explained. Wiley Interdisciplinary Reviews: Water 2, 359-392.

Vicente-Serrano, S. M., Beguería, S., and López-Moreno, J. I. (2010). A Multiscalar Drought Index Sensitive to Global Warming: The Standardized Precipitation Evapotranspiration Index. Journal of Climate 23, 1696-1718.

Vicente-Serrano, S. M., Gouveia, C., Camarero, J. J., Beguería, S., Trigo, R., López-Moreno, J. I., Azorín-Molina, C., Pasho, E., Lorenzo-Lacruz, J., Revuelto, J., Morán-Tejeda, E., and 
1

2

3

4

5

6

7

8

9

10

11

12

13

14

15

16

17

18

19

20

21

22

23

24

25

24

Sanchez-Lorenzo, A. (2013). Response of vegetation to drought time-scales across global land biomes. Proceedings of the National Academy of Sciences 110, 52-57.

Waseem, M., Ajmal, M., and Kim, T.-W. (2015). Development of a new composite drought index for multivariate drought assessment. Journal of Hydrology 527, 30-37.

WMO (2012). "Standardized Precipitation Index User Guide," Geneva.

(1)

8

9

10

1

2

3

4

5

6

(

8

9

20

1

2




\section{Tables:}

2

3 Table 1. The description of SPI classification (McKee et al., 1993).

\begin{tabular}{llc}
\hline Threshold Value & Class & Code \\
\hline$\geq 2.00$ & Very severe wet & W3 \\
1.99 to 1.50 & Severe wet & W2 \\
1.49 to 1.00 & Moderate wet & W1 \\
0.99 to 0.99 & Near normal & $\mathrm{N}$ \\
-1.00 to -1.49 & Moderate drought & D1 \\
-1.50 to -1.99 & Severe drought & D2 \\
$\leq-2.00$ & Very severe drought & D3 \\
\hline
\end{tabular}

4

5

6

7

8

9

10

11

12

13

14

15

16

17

18

19 
1 Table 2. The mathematical formulation of copula function used in the study (Genest and Favre,

2 2007).

\begin{tabular}{lcc}
\hline Copula & Bivariate Copula $C_{\theta}(u, v)$ & Parameters $\theta$ \\
\hline Student's t & $\int_{-\infty}^{t_{\theta}^{-1}(u)} \int_{-\infty}^{t_{\theta}^{-1}(v)} \frac{1}{2 \pi \sqrt{1-r^{2}}}\left\{1+\frac{x^{2}-2 r x y+y^{2}}{\theta\left(1-r^{2}\right)}\right\}^{-\frac{\theta+2}{2}} d x d y$ & $\theta>2, r \in[0,1]$ \\
& $t_{\theta}(x)=\int_{-\infty}^{x} \frac{\Gamma\left(\frac{\theta+1}{2}\right)}{\sqrt{\pi \theta} \Gamma(\theta / 2)}\left(1+y^{2} / \theta\right)^{-\frac{\theta+1}{2}} d y$ & \\
Normal & $\Phi_{2}\left(\Phi^{-1}(u), \Phi^{-1}(v), \rho\right)$ & $-1 \leq \rho \leq 1$ \\
Clayton & $\left(u^{-\theta}+v^{-\theta}-1\right)^{-1 / \theta}$ & $\theta \in(-1,0) \cup(0, \infty)$ \\
Frank & $-\frac{1}{\theta} \log \left[1+\frac{\left(e^{-\theta u}-1\right)\left(e^{-\theta v}-1\right)}{e^{-\theta}-1}\right]$ & $\theta \in-\infty, 0) \cup(0, \infty)$ \\
Joe & $1-\left[(1-u)^{\theta}+(1-v)^{\theta}-(1-u)^{\theta}(1-v)^{\theta}\right]^{1 / \theta}$ & $\theta \in 1, \infty)$ \\
\hline
\end{tabular}

3

4

5

6

7

8

9

10

11

12

13

14

15

16

17 
1 Table 3. Fitting the correlated functions on the simultaneous distribution of severity-duration of

2 drought obtained from CoDI and EnDI indices in the sudied sub-basins. (Gray rows show the best

3 copula function)

\begin{tabular}{|c|c|c|c|c|c|c|c|c|}
\hline \multirow{2}{*}{ Sub-basin } & \multicolumn{4}{|c|}{ CoDI } & \multicolumn{4}{|c|}{ EnDI } \\
\hline & Copula & Parameter & Statistic & P-value & Copula & Parameter & Statistic & P-value \\
\hline \multirow[t]{5}{*}{ HRB } & Frank & 8.94 & 0.03726 & 0.11 & Frank & 7.34 & 0.02160 & 0.68 \\
\hline & Joe & 4.29 & 0.02077 & 0.63 & Joe & 3.56 & 0.02694 & 0.24 \\
\hline & Clayton & 3.48 & 0.06268 & 0.00 & Clayton & 2.72 & 0.03702 & 0.14 \\
\hline & Normal & 0.84 & 0.03398 & 0.13 & Normal & 0.79 & 0.02350 & 0.61 \\
\hline & $\mathrm{T}$ & 0.84 & 0.03362 & 0.13 & $\mathrm{~T}$ & 0.79 & 0.02571 & 0.51 \\
\hline \multirow[t]{5}{*}{ KRB } & Frank & 6.58 & 0.03443 & 0.21 & Frank & 9.20 & 0.04319 & 0.04 \\
\hline & Joe & 3.22 & 0.05642 & 0.01 & Joe & 4.41 & 0.05480 & 0.01 \\
\hline & Clayton & 2.38 & 0.02487 & 0.65 & Clayton & 3.60 & 0.04237 & 0.07 \\
\hline & Normal & 0.75 & 0.02817 & 0.39 & Normal & 0.85 & 0.03661 & 0.10 \\
\hline & $\mathrm{T}$ & 0.75 & 0.02723 & 0.44 & $\mathrm{~T}$ & 0.85 & 0.03550 & 0.12 \\
\hline \multirow[t]{5}{*}{ BRB } & Frank & 6.69 & 0.02831 & 0.48 & Frank & 10.32 & 0.01805 & 0.83 \\
\hline & Joe & 3.27 & 0.03950 & 0.06 & Joe & 4.94 & 0.01667 & 0.77 \\
\hline & Clayton & 2.43 & 0.02820 & 0.48 & Clayton & 4.14 & 0.03370 & 0.11 \\
\hline & Normal & 0.76 & 0.02576 & 0.56 & Normal & 0.87 & 0.01904 & 0.58 \\
\hline & $\mathrm{T}$ & 0.76 & 0.02579 & 0.57 & $\mathrm{~T}$ & 0.87 & 0.02026 & 0.55 \\
\hline \multirow[t]{5}{*}{ DZRB } & Frank & 6.09 & 0.04188 & 0.11 & Frank & 13.58 & 0.03059 & 0.13 \\
\hline & Joe & 3.01 & 0.07590 & 0.00 & Joe & 6.51 & 0.02712 & 0.15 \\
\hline & Clayton & 2.16 & 0.02216 & 0.86 & Clayton & 5.72 & 0.04075 & 0.02 \\
\hline & Normal & 0.73 & 0.03895 & 0.15 & Normal & 0.92 & 0.02370 & 0.34 \\
\hline & $\mathrm{T}$ & 0.73 & 0.03863 & 0.16 & $\mathrm{~T}$ & 0.92 & 0.02265 & 0.44 \\
\hline \multirow[t]{5}{*}{ DERB } & Frank & 8.88 & 0.02399 & 0.57 & Frank & 8.02 & 0.01788 & 0.89 \\
\hline & Joe & 4.27 & 0.03658 & 0.04 & Joe & 3.87 & 0.02516 & 0.28 \\
\hline & Clayton & 3.45 & 0.02457 & 0.57 & Clayton & 3.04 & 0.02397 & 0.55 \\
\hline & Normal & 0.84 & 0.02070 & 0.77 & Normal & 0.81 & 0.01512 & 0.97 \\
\hline & $\mathrm{T}$ & 0.84 & 0.02027 & 0.79 & $\mathrm{~T}$ & 0.81 & 0.01569 & 0.97 \\
\hline \multirow[t]{5}{*}{ SRB } & Frank & 8.99 & 0.03119 & 0.28 & Frank & 10.80 & 0.03123 & 0.21 \\
\hline & Joe & 4.32 & 0.02284 & 0.61 & Joe & 5.17 & 0.02103 & 0.66 \\
\hline & Clayton & 3.50 & 0.05475 & 0.01 & Clayton & 4.37 & 0.05316 & 0.00 \\
\hline & Normal & 0.84 & 0.03017 & 0.29 & Normal & 0.88 & 0.03081 & 0.19 \\
\hline & $\mathrm{T}$ & 0.84 & 0.03080 & 0.27 & $\mathrm{~T}$ & 0.88 & 0.03063 & 0.20 \\
\hline \multirow[t]{5}{*}{ MRB } & Frank & 15.15 & 0.02025 & 0.48 & Frank & 14.66 & 0.01905 & 0.72 \\
\hline & Joe & 7.27 & 0.02376 & 0.12 & Joe & 7.04 & 0.01820 & 0.68 \\
\hline & Clayton & 6.50 & 0.02687 & 0.14 & Clayton & 6.26 & 0.02867 & 0.19 \\
\hline & Normal & 0.93 & 0.01657 & 0.76 & Normal & 0.93 & 0.01609 & 0.91 \\
\hline & $\mathrm{T}$ & 0.93 & 0.01654 & 0.75 & $\mathrm{~T}$ & 0.93 & 0.01612 & 0.93 \\
\hline
\end{tabular}


1 Table 4. Comparing drought severity (S) and duration (D) for different return periods (T) along

2 with the return period of bivariate drought severity-duration (T(S,D)) based on CoDI and EnDI in

3 the sub-basins.

\begin{tabular}{|c|c|c|c|c|c|c|c|}
\hline \multirow{2}{*}{ Sub-basin } & \multirow{2}{*}{ T (years) } & \multicolumn{3}{|c|}{ CoDI } & \multicolumn{3}{|c|}{ EnDI } \\
\hline & & $\mathbf{S}$ & D & T(S,D) (years) & $\mathbf{S}$ & D & T(S,D) (years) \\
\hline \multirow[t]{6}{*}{ HRB } & 2 & 3.4 & 6.0 & 2.5 & 2.8 & 4.2 & 2.3 \\
\hline & 5 & 8.0 & 11.5 & 6.3 & 6.5 & 6.4 & 5.9 \\
\hline & 10 & 11.4 & 16.2 & 12.6 & 9.3 & 8.0 & 11.8 \\
\hline & 20 & 14.8 & 21.5 & 25.3 & 12.1 & 9.6 & 23.6 \\
\hline & 50 & 19.4 & 29.6 & 63.2 & 15.8 & 11.8 & 59.0 \\
\hline & 100 & 22.8 & 36.6 & 126.5 & 18.6 & 13.6 & 117.9 \\
\hline \multirow[t]{6}{*}{ KRB } & 2 & 3.96 & 5.26 & 2.41 & 3.78 & 5.66 & 2.50 \\
\hline & 5 & 7.12 & 8.05 & 10.20 & 6.44 & 7.55 & 11.50 \\
\hline & 10 & 9.14 & 9.84 & 34.32 & 8.08 & 8.54 & 40.48 \\
\hline & 20 & 10.98 & 11.48 & 124.24 & 9.54 & 9.35 & 150.79 \\
\hline & 50 & 13.22 & 13.54 & 727.31 & 11.30 & 10.24 & 900.60 \\
\hline & 100 & 14.81 & 15.02 & 2843.40 & 12.52 & 10.83 & 3546.49 \\
\hline \multirow[t]{6}{*}{ BRB } & 2 & 4.67 & 6.42 & 2.76 & 4.52 & 5.92 & 2.34 \\
\hline & 5 & 7.30 & 8.63 & 8.51 & 6.58 & 7.52 & 7.69 \\
\hline & 10 & 8.98 & 9.78 & 18.87 & 7.66 & 8.32 & 21.61 \\
\hline & 20 & 10.55 & 10.73 & 40.55 & 8.55 & 8.96 & 67.96 \\
\hline & 50 & 12.51 & 11.78 & 107.93 & 9.55 & 9.66 & 354.27 \\
\hline & 100 & 13.93 & 12.47 & 222.72 & 10.22 & 10.11 & 1321.69 \\
\hline \multirow[t]{6}{*}{ DZRB } & 2 & 5.09 & 6.12 & 2.82 & 4.73 & 6.18 & 2.29 \\
\hline & 5 & 7.46 & 8.55 & 12.20 & 6.56 & 8.05 & 8.57 \\
\hline & 10 & 8.77 & 10.18 & 41.55 & 7.51 & 9.01 & 26.68 \\
\hline & 20 & 9.89 & 11.76 & 151.63 & 8.30 & 9.79 & 91.39 \\
\hline & 50 & 11.16 & 13.84 & 892.64 & 9.18 & 10.64 & 513.10 \\
\hline & 100 & 12.02 & 15.42 & 3496.99 & 9.78 & 11.20 & 1974.36 \\
\hline \multirow[t]{6}{*}{ SRB } & 2 & 4.30 & 5.39 & 2.57 & 3.38 & 5.60 & 2.27 \\
\hline & 5 & 8.25 & 9.19 & 6.48 & 6.27 & 8.74 & 6.92 \\
\hline & 10 & 10.88 & 12.16 & 12.97 & 8.16 & 10.76 & 18.25 \\
\hline & 20 & 13.33 & 15.31 & 25.94 & 9.89 & 12.64 & 54.12 \\
\hline & 50 & 16.38 & 19.85 & 64.84 & 12.04 & 14.98 & 266.40 \\
\hline & 100 & 18.59 & 23.60 & 129.68 & 13.57 & 16.68 & 968.15 \\
\hline \multirow[t]{6}{*}{ DRB } & 2 & 4.26 & 6.15 & 2.56 & 4.21 & 5.42 & 2.73 \\
\hline & 5 & 7.63 & 8.39 & 7.50 & 7.06 & 7.08 & 8.83 \\
\hline & 10 & 9.78 & 9.57 & 16.21 & 8.81 & 8.14 & 20.05 \\
\hline & 20 & 11.73 & 10.54 & 34.22 & 10.35 & 9.14 & 43.79 \\
\hline & 50 & 14.11 & 11.63 & 89.70 & 12.20 & 10.40 & 118.24 \\
\hline & 100 & 15.79 & 12.36 & 183.70 & 13.49 & 11.34 & 245.72 \\
\hline \multirow[t]{6}{*}{ MRB } & 2 & 3.64 & 5.44 & 2.13 & 4.47 & 5.88 & 2.46 \\
\hline & 5 & 6.39 & 7.55 & 5.90 & 6.48 & 7.55 & 6.74 \\
\hline & 10 & 8.11 & 8.69 & 12.61 & 7.58 & 8.60 & 14.09 \\
\hline & 20 & 9.67 & 9.62 & 26.77 & 8.51 & 9.58 & 29.07 \\
\hline & 50 & 11.55 & 10.68 & 71.96 & 9.57 & 10.82 & 74.65 \\
\hline & 100 & 12.87 & 11.38 & 151.51 & 10.28 & 11.73 & 151.31 \\
\hline
\end{tabular}

4 
1 Table 5. Spearman correlation coefficient between NDVI and drought indices with zero-month

$2 \operatorname{lag}(\operatorname{Lag}=0)$ and one-month lag $(\operatorname{Lag}=1)$ in the studied sub-basins.

\begin{tabular}{lccccccc}
\hline & \multicolumn{1}{c}{ NDVI in the subbasin } \\
\cline { 2 - 8 } Drought Index & HRB & KRB & BRB & DZRB & SRB & DERB & MRB \\
\hline SPI (Lag=0) & 0.534 & 0.609 & 0.659 & 0.648 & 0.620 & 0.558 & 0.256 \\
SDI (Lag=0) & 0.393 & 0.552 & 0.608 & 0.659 & 0.373 & 0.465 & $\mathbf{0 . 6 4 1}$ \\
CoDI (Lag=0) & 0.514 & 0.622 & 0.660 & 0.664 & 0.579 & 0.547 & 0.514 \\
EnDI (Lag=0) & $\mathbf{0 . 5 6 4}$ & $\mathbf{0 . 6 4 4}$ & $\mathbf{0 . 6 9 0}$ & $\mathbf{0 . 7 0 2}$ & $\mathbf{0 . 6 2 1}$ & $\mathbf{0 . 5 7 0}$ & 0.552 \\
\hline SPI (Lag=1 month) & 0.572 & 0.589 & $\mathbf{0 . 5 9 2}$ & 0.573 & $\mathbf{0 . 5 5 0}$ & 0.477 & 0.496 \\
SDI (Lag=1 month) & 0.354 & 0.559 & 0.482 & $\mathbf{0 . 6 5 6}$ & 0.289 & 0.303 & 0.600 \\
CoDI (Lag=1 month) & 0.505 & 0.609 & 0.554 & 0.612 & 0.472 & 0.410 & 0.678 \\
EnDI (Lag=1 month) & $\mathbf{0 . 5 9 3}$ & $\mathbf{0 . 6 3 0}$ & 0.589 & 0.645 & 0.529 & $\mathbf{0 . 4 7 8}$ & $\mathbf{0 . 6 9 5}$ \\
\hline
\end{tabular}

3

4

5

6

7

8

9

10

11

12

13

14

15

16

17

18 


\section{Figures:}

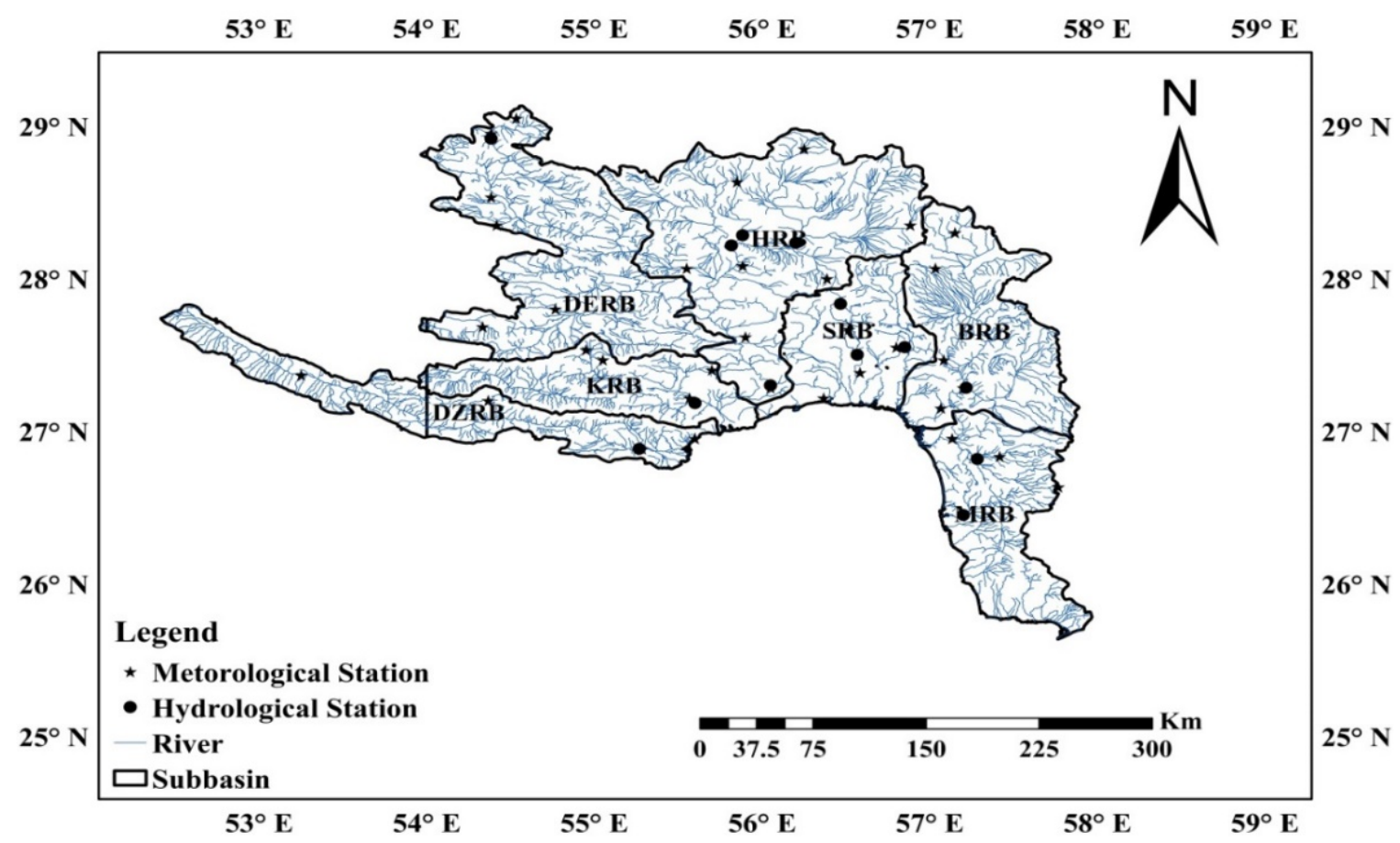

6

9

Fig. 1. The sub-basins and the geographical situations of meteorological and hydrological stations used in this study. 
4

5

6

7

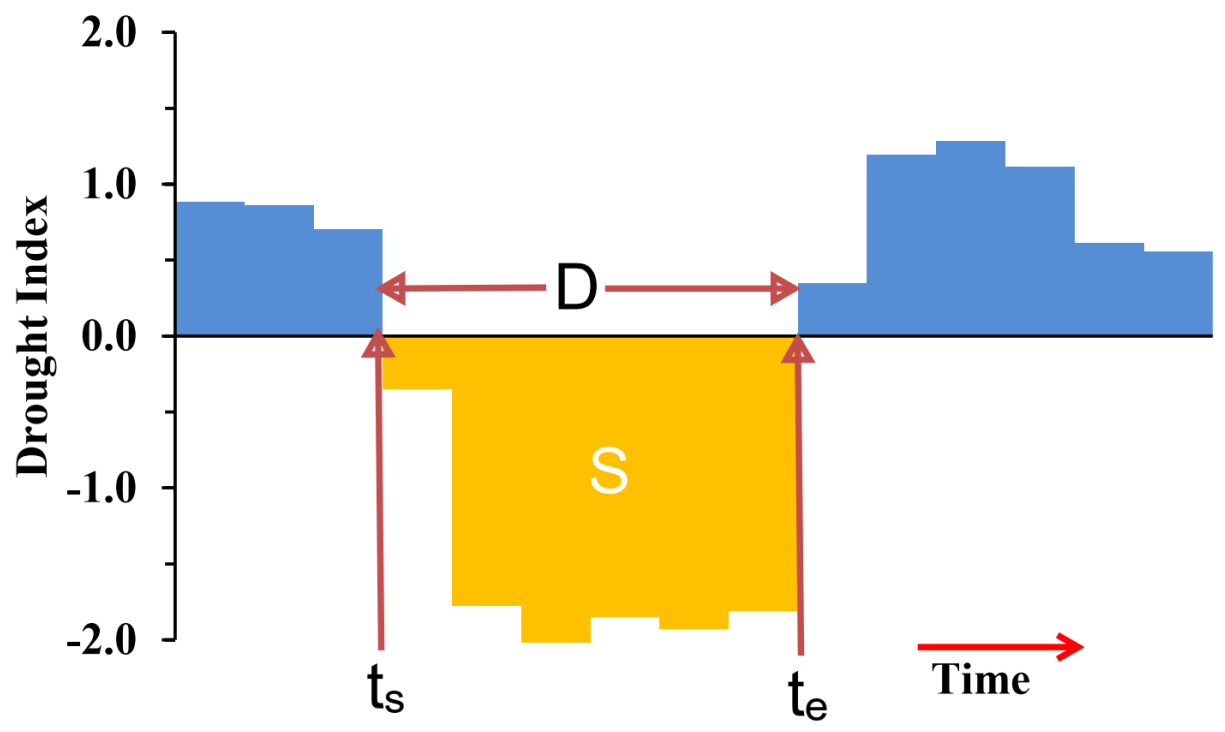

8 Fig. 2. Characteristics drought severity (S) and duration (D) $\left(t_{s}\right.$ and $t_{e}$ are the beginning point and 9 the ending point of drought, respectively).

10

11

12

13

14

15

16 

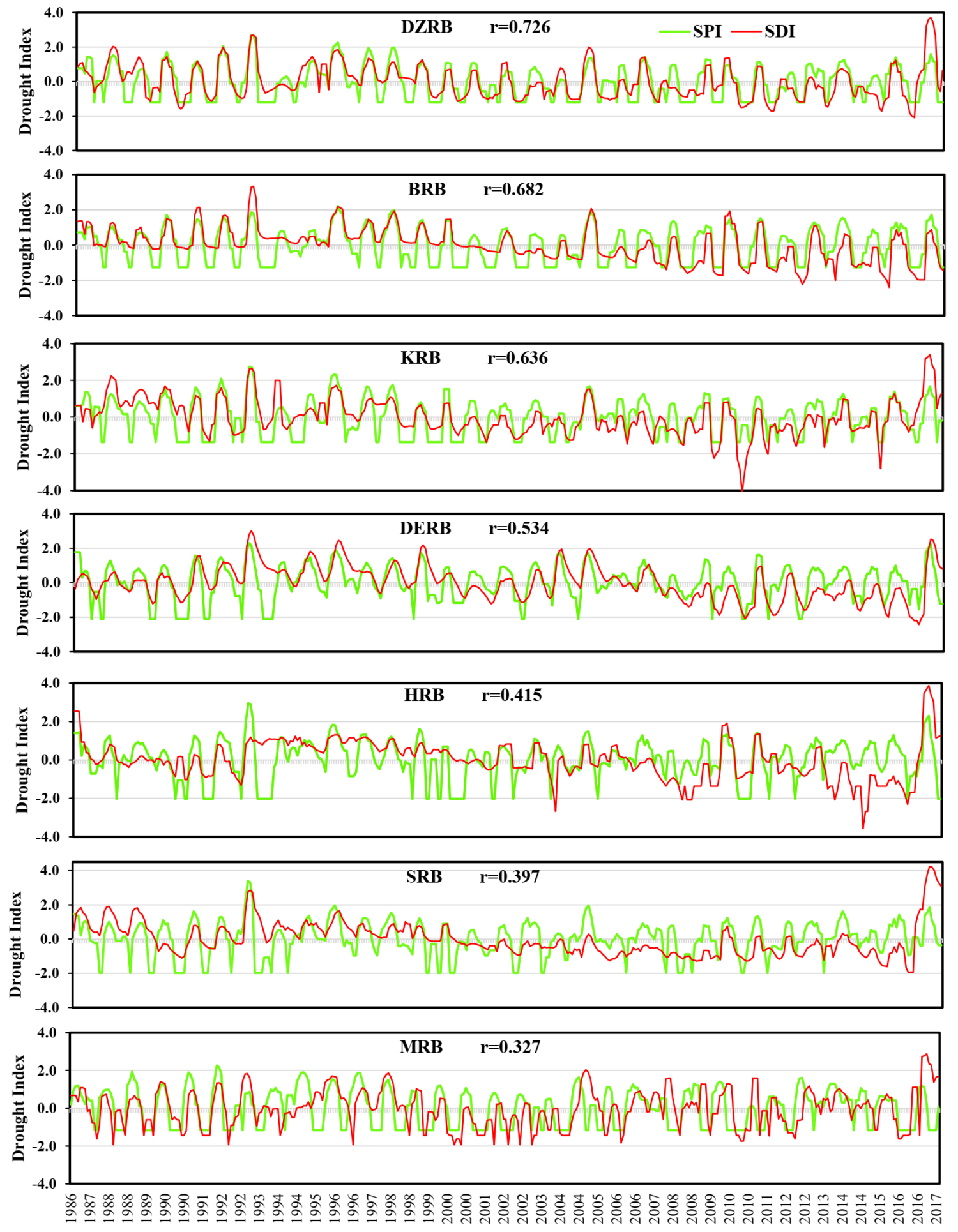

Fig. 3. Variations of SPI and SDI in the sub-basins of the study area ( $r$ is the Spearman correlation

3 coefficient between SPI and SDI). 

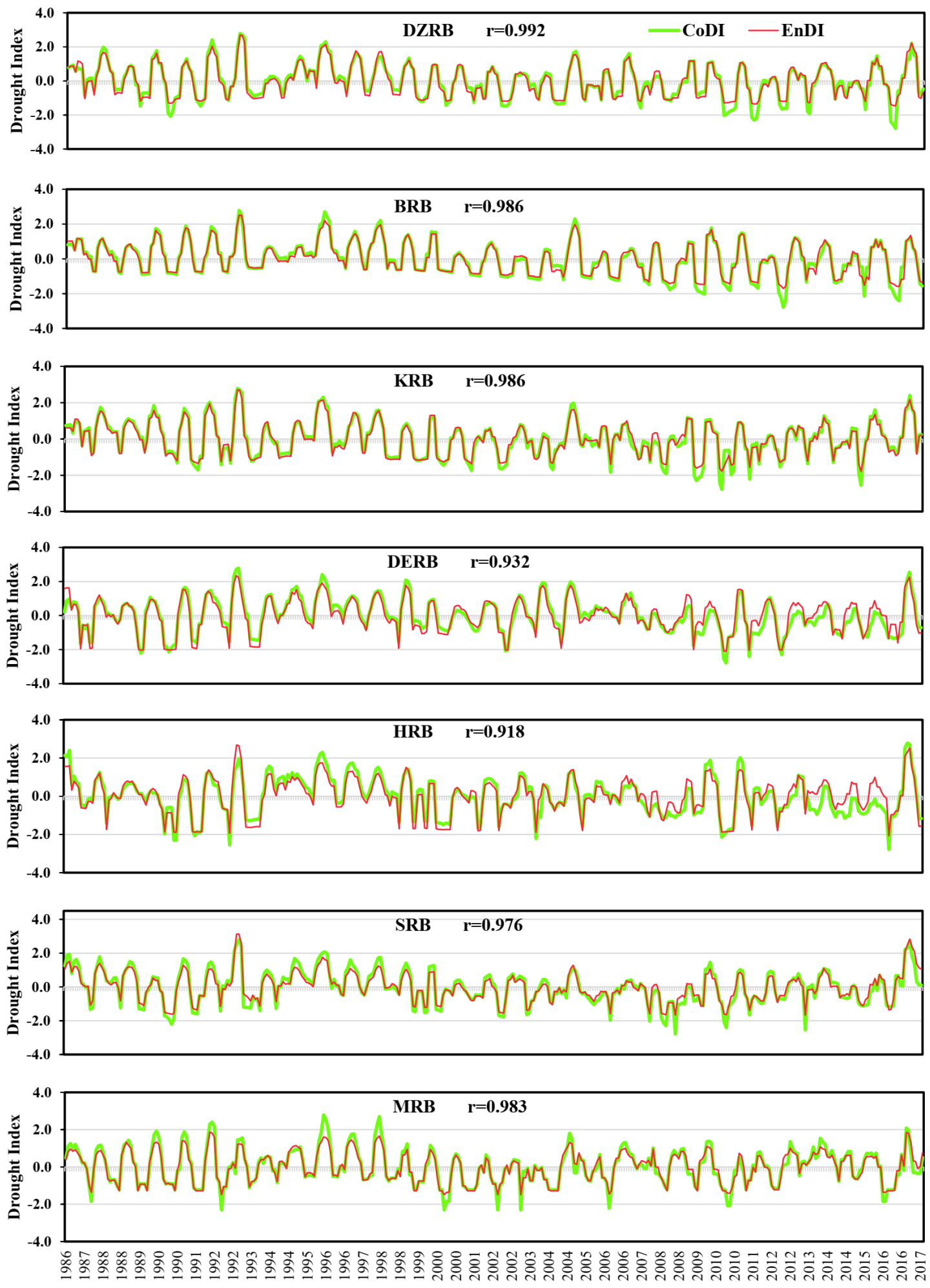

2 Fig. 4. Variations of CoDI and EnDI in the sub-basins of the study area ( $r$ is the Spearman

3 correlation coefficient between CoDI and EnDI). 


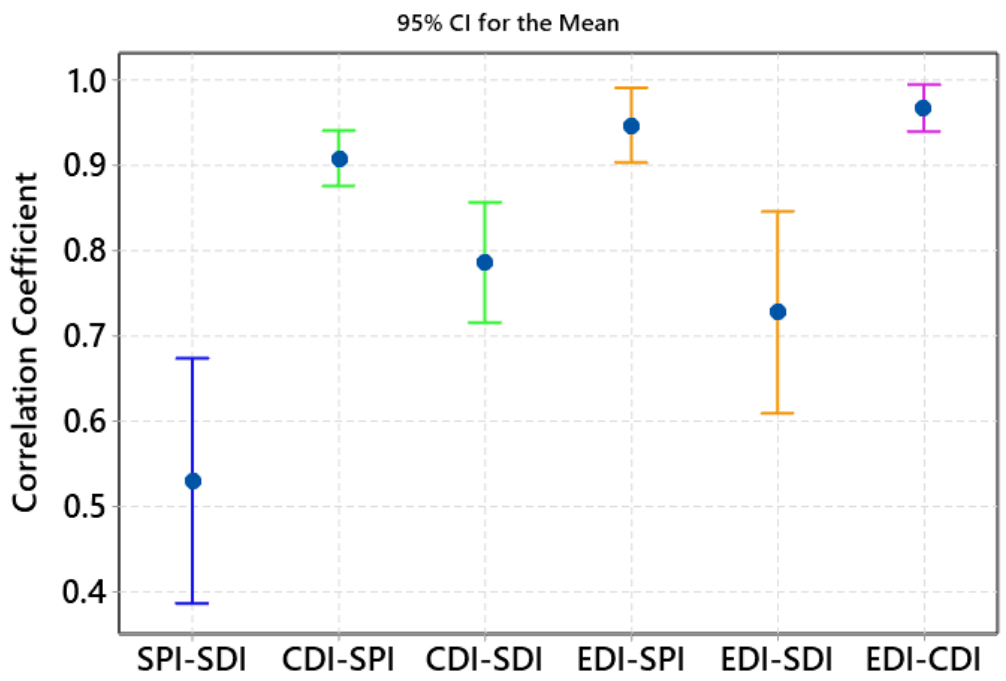

7 Fig. 5. Mean and the 95\% confidence level of Spearman correlation coefficient between drought 8 indices across the studied sub-basins.

9

10

11

12

13

14

15

16

17 

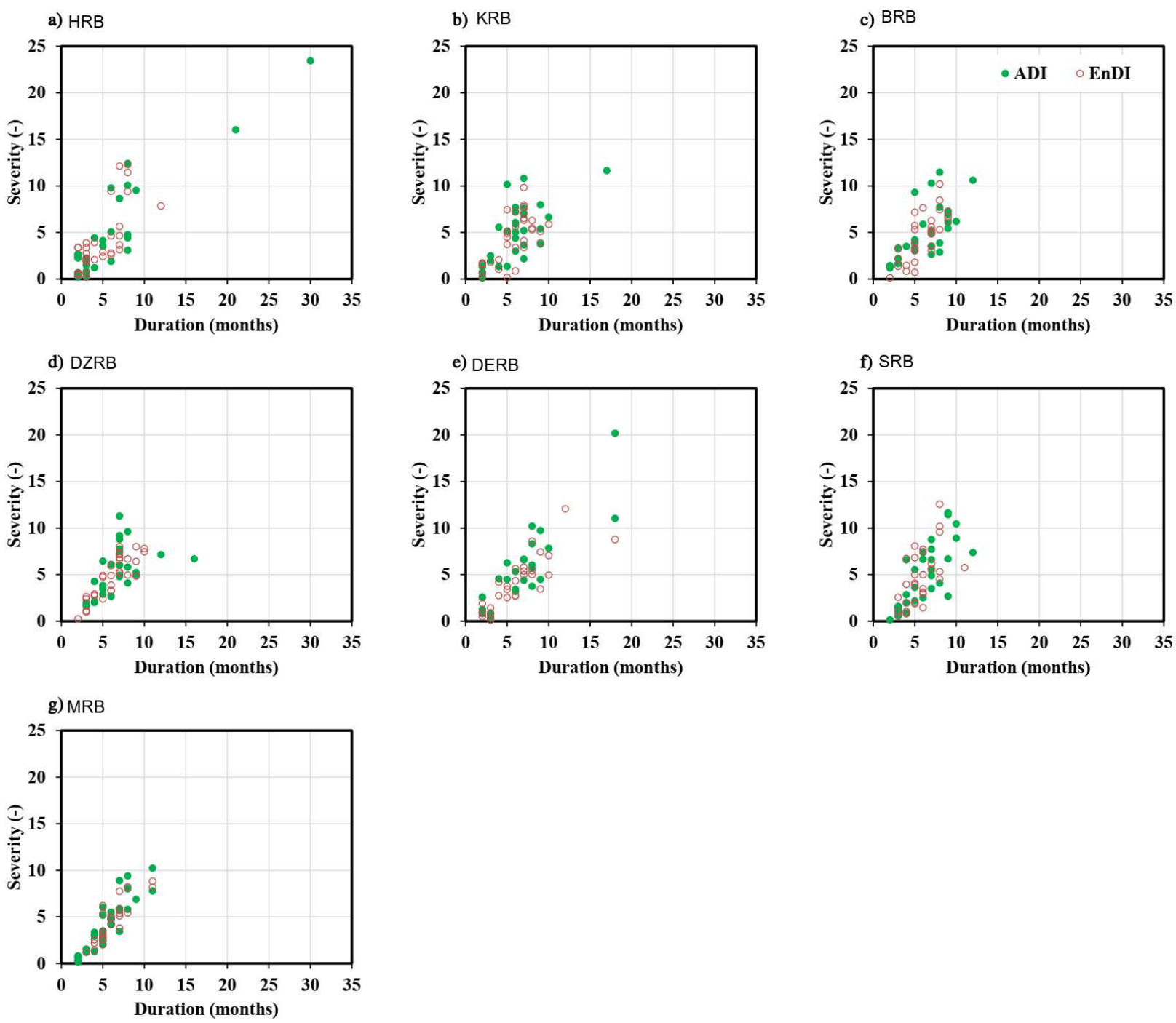

4 Fig. 6. Scatter diagrams of drought duration and severity of two hybrid indices CoDI and EnDI in the studied sub-basins. 

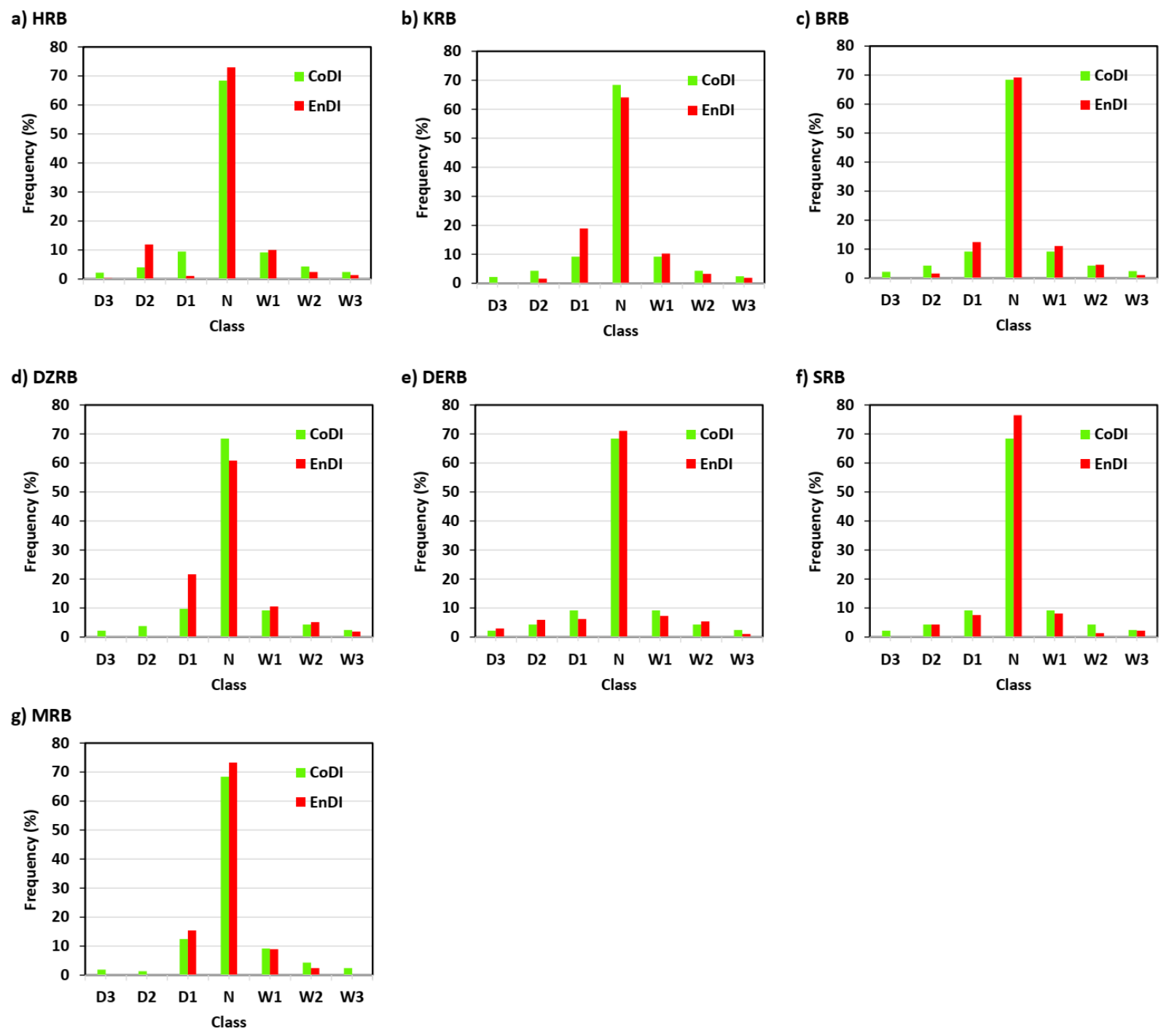

Fig. 7. Frequency of the different classes of CoDI and EnDI in the studied sub-basins. 


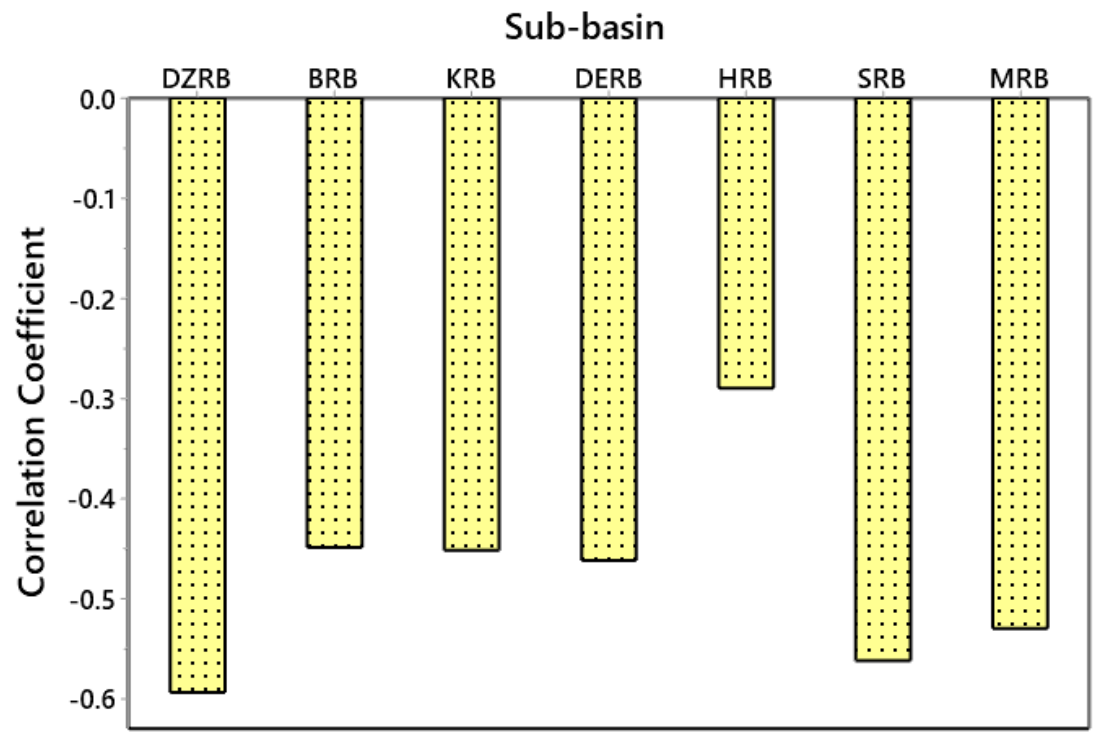

6

7 Fig. 8. Spearman correlation coefficient between NDVI and LST in the studied sub-basins. All 8 correlations are significant at the $95 \%$ confidence level.

9

10

11

12

13

14

15

16 